\title{
Reeducação das relações étnico-raciais e ensino de Áfricas: formação continuada de professores (NEAB-UDESC/SC, 2014)
}

\author{
Karla Leandro Rascke* \\ Pontifícia Universidade Católica de São Paulo \\ Paulino de Jesus Francisco Cardoso** \\ Universidade do Estado de Santa Catarina \\ Graziela dos Santos Lima*** \\ Universidade do Estado de Santa Catarina \\ Ana Julia Pacheco**** \\ Universidade do Estado de Santa Catarina
}

Resumo A presente proposta de trabalho visa discutir e avaliar o curso de formação de professores(as) realizado pelo Núcleo de Estudos Afro-Brasileiros da Universidade do Estado de Santa Catarina (NEAB-UDESC) a partir do Programa do Governo Federal UNIAFRO-IV (Brasil) voltado para a discussão sobre relações étnico-raciais, história da África e da diáspora africana. Objetivamos realizar uma análise acerca do curso, seus objetivos e metodologia, bem como discutir os resultados alcançados com as discussões propostas nos fóruns de dabate de cada módulo e das atividades finais. Concluímos que a formação possui resultado exitoso, atingindo importante número de professores(as) de todas as áreas do conhecimento nas mais variadas regiões do estado de Santa Catarina, ampliando as possibilidades de abordagem acerca de conteúdos sobre educação das relações étnico-raciais, história da África e da diáspora africana no Brasil, em especial.

PALAVRAS-CHAVE: História; Ensino e formação continuada; Educação das relações étnico-raciais. 
Karla Leandro Rascke - Paulino de Jesus Francisco Cardoso - Graziela dos Santos Lima Ana Julia Pacheco

\title{
Re-education of ethnic-racial relations and African education: continuing teacher education (NEAB-UDESC/SC, 2014)
}

\begin{abstract}
The proposed work aims to discuss and evaluate the course of teacher training (as) conducted by the Center for Afro-Brazilian States State University of Santa Catarina (NEAB-UDESC) from the Federal Government UNIAFRO -IV Program (Brazil) facing the discussion of ethnic and race relations, history of Africa and the African Diaspora. We aim to perform an analysis about the course, its objectives and methodology as well as discuss the results achieved with the discussions proposed in dabate forums of each module and the final 0 activities. We conclude that the training has successful outcome, reaching large numbers of teachers from all areas of knowledge in various regions of the state of Santa Catarina, expanding the approach of possibilities about material on education of ethnic-racial relations, history Africa and the African Diaspora in Brazil in particular.
\end{abstract}

KEYWORDS: History; Education and continuing education; Education of racial-ethnic relations.

\section{Introdução}

Decorridos 15 anos da sanção da Lei Federal $10.639 / 03^{1}$, pelo presidente da República Luiz Inácio Lula da Silva, muitas ações foram efetuadas, no sentido de implementar esta norma legal, uma das maiores conquistas do Movimento Negro brasileiro. Faz-se necessário enfatizar que esta é uma das poucas leis surgidas do e no movimento social, adotadas por parlamentares organicamente vinculados às organizações antirracistas e a um projeto de reconhecimento político das demandas das populações de origem africana em nosso país.

O Núcleo de Estudos Afro-Brasileiros (NEAB-UDESC), desde 2003, tem se inserido em estratégias e ações que visam a implementação desta Lei, pautada na obrigatoriedade do ensino de história e cultura africana e afro-brasileira nos currículos escolares, com a especificidade de centrar sua ação em atividades que possibilitem aos gestores municipais e estaduais, professores(as) da rede de ensino, formação adequada, em especial na educação básica. Uma das ações voltadas para a temática foi sistematizada pelo NEAB-UDESC na forma de um curso de formação de professores(as), que, por meio da Edição IV do Programa UNIAFRO, MEC/SECADI ${ }^{2}$, tornou possível a elaboração de material didático acessível a linguagem dos(as) professores(as) da rede e oficinas práticas.

Compete ressaltar que os cursos de extensão, capacitação, aperfeiçoamento e especialização, ações financiadas pelo Ministério da Educação via Secretaria de Educação Continuada, Alfabetização, Diversidade e Inclusão (SECADI), constituem propostas das universidades para atendimento às inúmeras demandas de professores e professoras, gestores e gestoras e demais profissionais envolvidos com os processos 
educativos e que necessitam de formação adequada nas temáticas de Áfricas, diáspora africana e relações raciais no Brasil.

O projeto Diversidade Étnica na Educação, financiado pelo Programa UNIAFRO IV, foi direcionado à formação de gestores(as) escolares, professores(as) da rede pública e particular de ensino e graduandos(as) dos cursos de licenciaturas e pedagogia, bem como educadores(as) sociais e militantes do Movimento Negro ou entidades voltadas à temática.

A formação foi realizada em três ações, a saber: formação inicial, extensão e aperfeiçoamento, conformado 3 cursos distintos, de acordo com o público e as demandas de cada perfil de profissionais. Quanto aos termos do presente texto, devido à estrutura e envolvimento amplo de todas as regiões do estado de Santa Catarina, aprofundamo-nos nas análises e resultados a partir da Ação 1, voltada para formação continuada de professores e professoras da rede de Educação Básica.

Como aponta Anderson Oliva, é fundamental que alunos e alunas de graduação (formação inicial) tenham oportunidade de "conhecer a história, a geografia, as literaturas, as artes ou as filosofias africanas", percebendo que o não acesso a estes conhecimentos e debates dificultam "combatermos as imprecisões e incapacidades de nossos olhares sobre os africanos e sobre nós mesmos" (OLIVA, 2006, p. 190). Como em muitos cursos de licenciaturas ainda há uma defasagem quanto ao cumprimento da Lei e abordagem das temáticas necessárias à formação de professores(as), necessitamos incluir estes debates e possibilidades na formação continuada destes profissionais, dos diferentes níveis de ensino e áreas de atuação e lidar com questões relativas à educação das relações étnico-raciais, bem como o estudo de história e cultura afro -brasileira e africana em suas múltiplas dimensões e especificidades. Neste sentido, este texto apresenta como organizamos a proposta do curso e os desafios no sentido de produzir material e realizar a formação nesta temática, para diferentes áreas do conhecimento escolar.

\section{A proposta do curso e a implementação da lei federal 10.639/03}

A formação de professores(as) das diferentes redes e modalidades de ensino, atuantes no estado de Santa Catarina, realizada no formato semipresencial, contou com parte da ação, a realização na modalidade a distância, via plataforma moodle ${ }^{4}$, e encontros presenciais realizados aos sábados (em cada polo), totalizando uma carga horária de 180 horas.

Conforme aponta Anderson Oliva, necessitamos organizar iniciativas em diferentes âmbitos para concretizar propostas educacionais e de pesquisa que voltem suas atenções às Áfricas, suas diásporas e as relações raciais no Brasil. Neste sentido, o autor sugere algumas possibilidades que deveriam ser reforçadas: "o aumento das pesquisas sobre a história da África; o incentivo às novas publicações e traduções; a introdução de disciplinas específicas nas licenciaturas; a oferta de cursos de pós-graduação e a modificação dos livros didáticos" (OLIVA, 2006, p. 187). 


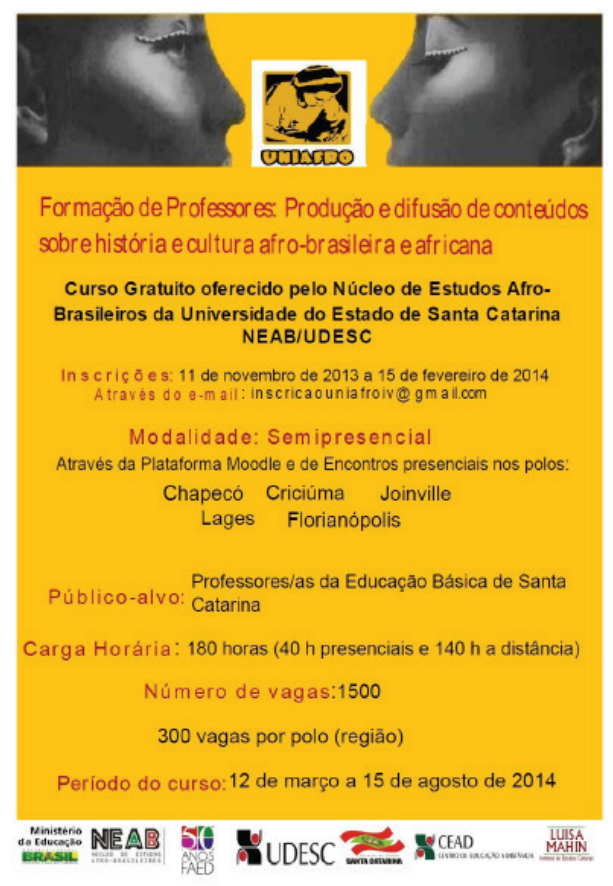

Diante das inúmeras demandas que envolvem a formação inicial e continuada de professores(as), bem como a necessidade de pesquisas que atentem para os temas africanos, o NEAB-UDESC volta sua atenção a estas questões, preparando material didático específico e permitindo que professores(as) recebam formação adequada às demandas e realidades escolares onde atuam, visto que nem sempre a formação inicial (graduação) aborda, em suas matrizes curriculares e cursos, tais assuntos, perspectivas e questionamentos.

O intuito da formação foi proporcionar estudos e reflexões junto a professores(as), construindo instrumental teórico e metodológico para implementação da Lei Federal 10.639/03 nas escolas onde lecionavam ou que gerenciavam. Dessa forma, o conteúdo ministrado em 5 (cinco) módulos ${ }^{5}$, contou com a participação de professores(as) formadores(as) especializados(as) em temas de interesse direto do curso e de sua proposta. Cada assunto abordado teve como suporte teórico o material didático desenvolvido pelos próprios professores(as) formadores(as), pesquisadores(as) do NEAB-UDESC ${ }^{6}$.

A cada módulo, professores e professoras que realizaram o curso tinham que responder a um fórum relacionado ao assunto, sendo que por meio deste, poderiam problematizar e sanar as suas dúvidas com relação ao assunto abordado. Além 
disso, o fórum serviu, muitas vezes, para expor experiências vividas em sala de aula e nos diversos âmbitos do convívio escolar, permitindo articulações teóricas e práticas com os aprendizados construídos ao longo do curso.

No decorrer do curso, nos momentos de formações presenciais, contamos também com a realização de minicursos e oficinas. Os minicursos constituíram complemento para o amadurecimento dos assuntos abordados via $\mathrm{EaD}$. As oficinas possibilitaram evidenciar com os(as) professores(as) como desenvolver metodologias, olhares e abordagens para conteúdos relacionados às Áfricas e diásporas africanas, explicando de forma visual, como podem implementar a Lei Federal 10.639/03, valendo-se de objetos, imagens e questões teóricas relacionadas com a temática Africana e Afro-Brasileira.

A partir dos conhecimentos obtidos, o trabalho final, a construção de um plano de aula sobre a temática de Áfricas e educação das relações étnico-raciais, propunha abarcar os conteúdos ministrados, devendo ser pensado e utilizado na escola onde os(as) professores(as) lecionavam. O trabalho final ganhou corpo devido aos referenciais bibliográficos, teóricos e metodológicos enfocados durante o curso e que permitiram construções diversas a respeito das temáticas exploradas e desenvolvidas no final do curso.

\section{A organização do material didático}

Produzir material didático com a finalidade específica do curso, em especial pensando em dificuldades e expectativas de professores e professoras em relação a conteúdos e perspectivas propostas para nossa formação, demandava uma linguagem apropriada e questões mínimas para compreensão dos sentidos múltiplos das Áfricas e das experiências e vivências da diáspora.

Neste sentido, a sistematização de temas e o formato utilizado para desenvolvimento dos conteúdos pautou-se em meios de associar perspectivas teóricas e metodológicas capazes de despertar nos(as) docentes da Educação Básica um entendimento mais amplo sobre o continente africano, sua diversidade e histórias. Do mesmo modo, pensamos em questões que discutissem cotidianamente a realidade brasileira em termos de relações raciais na sociedade e no espaço escolar, bem como, perceber a presença e a atuação de origem africana no Brasil, em especial Santa Catarina, estado marcado equivocadamente com o ideário de uma Europa ao Sul do Brasil ${ }^{7}$.

Um dos pilares de embasamento teórico utilizado para a construção do material didático elaborado para o curso, bem como os materiais bibliográficos e audiovisuais disponibilizados para consulta e diálogo nos fóruns, consistiu em formas de apresentar e discutir temas e abordagens combatendo estereótipos negativos e visões equivocadas sobre vivências africanas e suas relações com os demais continentes. $\mathrm{O}$ material do curso foi elaborado por professores e professoras qualificados(as) na temática e construíram narrativas reflexivas com base em temas norteadores de cada capítulo $^{8}$, sistematizados em 4 Módulos distintos, a constar: Módulo 1 - Introdução; Módulo 2 - Relações Étnico-Raciais na Sociedade; Módulo 3 - Introdução a História 
da África; Módulo 4 - História das Populações de Origem Africana no Brasil. Os profissionais da educação contratados para elaboração dos materiais didáticos do curso possuíam formação em educação e história (com mestrado e/ou doutorado), dentro de pesquisas e abordagens referentes à história das Áfricas e da diáspora e educação das relações étnico-raciais 9 .

No módulo 1, enfocamos reflexões acerca de "termos, expressões e sentidos relacionados ao dia a dia, às vivências escolares, às experiências em ambientes de trabalho, rodas de conversas, espaços familiares" (CARDOSO; RASCKE, 2014, p. 11), priorizando questões e debates que envolvem o ser humano no seu cotidiano em termos de relações sociais e raciais. Assim, propusemos compreender os sentidos dos termos negro, afrodescendente, políticas de ação afirmativa, racismo, Lei Federal 10.639/03 e tantas outras referências conceituais que pautam as relações dos sujeitos constantemente.

Quanto ao módulo 2, as abordagens enfatizaram as relações raciais, "atentando para reflexões em torno dos currículos escolares e dos materiais didáticos que servem de suporte aos processos de escolarização, bem como a compreensão das lutas do Movimento Negro e os avanços provocados pelas conquistas no âmbito das ações afirmativas" (CARDOSO; RASCKE, 2014, p. 42). Intentamos analisar os estereótipos e os conteúdos dispostos em materiais didáticos que abordam África, relações raciais, escravidão e temas relativos às populações de origem africana na diáspora, observando lutas e embates em torno de uma educação mais plural, bem como destacando as ações do Movimento Negro brasileiro e de intelectuais e militantes antirracistas para a implementação da Lei Federal 10.639/03.

Em relação aos estudos envolvendo História da África, o módulo 3 pretendeu abordar aspectos introdutórios da história do continente e suas múltiplas realidades e perspectivas. Nos dizeres de Oliva, a respeito da fundamental importância dos estudos envolvendo história e cultura africana, a "África possui tantas escolas de pensadores, artistas, escultores, intelectuais e tantas contribuições para o entendimento da construção do patrimônio histórico-cultural da humanidade que é inadmissível simplesmente não estudá-la" (OLIVA, 2006, p. 190).

Em se tratando de uma temática ainda recente nas salas de aula da educação básica, o estudo das Áfricas permite conectar elementos culturais africanos à realidade de experiências vividas no Brasil, bem como conhecer dinâmicas internas do continente e sua interação/ inter-relação com os demais continentes. Longe da ideia de um continente isolado, marcado pelas "impossibilidades" do deserto do Saara, sabemos que o continente africano sempre esteve em relação intensa com povos de outros continentes e também, importante destacar, suas próprias populações - diversas -, interagiam, trocavam produtos materiais e culturais (CARDOSO; RASCKE, 2014, p. 94).

Atentamos para a importância de uma produção sobre Áfricas que amplie as abordagens envolvendo o continente, suas histórias e memórias, impedindo a perpetuação de uma narrativa de vitimização do continente e de uma ideia equivocada 
de "continente da escravidão". Atuamos no sentido de criticar esta visão simplista e equivocada, em que "o continente é enxergado de modo distorcido e unilateral, impedindo que suas histórias sejam discutidas de forma aprofundada, para além das marcas da escravidão e do colonialismo" (CARDOSO; RASCKE, 2014, p. 94).

Finalizando os materiais e apontamentos, 5 capítulos sobre diáspora africana no Brasil contemplam as discussões presentes no módulo 4. A proposta deste módulo abrangeu bibliografias sobre Brasil em termos da presença africana, vislumbrando

ampliar as possibilidades de olhares sobre histórias de homens e mulheres simples, muitos deles cativos, mas que atuaram cultural, econômica e socialmente na construção da sociedade brasileira. Tratam-se de sujeitos que criaram irmandades, fundaram jornais e clubes recreativos, organizaram escolas e clubes de futebol, mobilizaram autoridades e conhecidos para suas lutas, desfilaram em ruas diversas nos momentos de carnaval, e de festas aos seus santos padroeiros, cultuaram Nossa Senhora em seus Cacumbis, cultivaram seus alimentos, venderam seus serviços e lidaram com uma sociedade dura desde os tempos coloniais (CARDOSO; RASCKE, 2014, p. 166).

Os materiais produzidos para o curso compuseram uma obra coletiva e resultaram na publicação do livro "Formação de Professores: produção e difusão de conteúdos sobre história afro-brasileira e africana" lançado em 2014 pela editora da Imprensa Oficial do Estado de Santa Catarina. Aliado a este material didático que compunha o texto base de cada capítulo trabalhado durante uma semana no ambiente virtual de aprendizagem, outros materiais de apoio em diversos formatos e mídias foram utilizados para ampliar o arsenal de conteúdo e abordagens sobre a temática, como bem destacamos a seguir, no item relacionado ao ambiente virtual de aprendizagem.

Figura 2 - Livro do curso. Material didático produzido por professores(as) especialistas na temática.

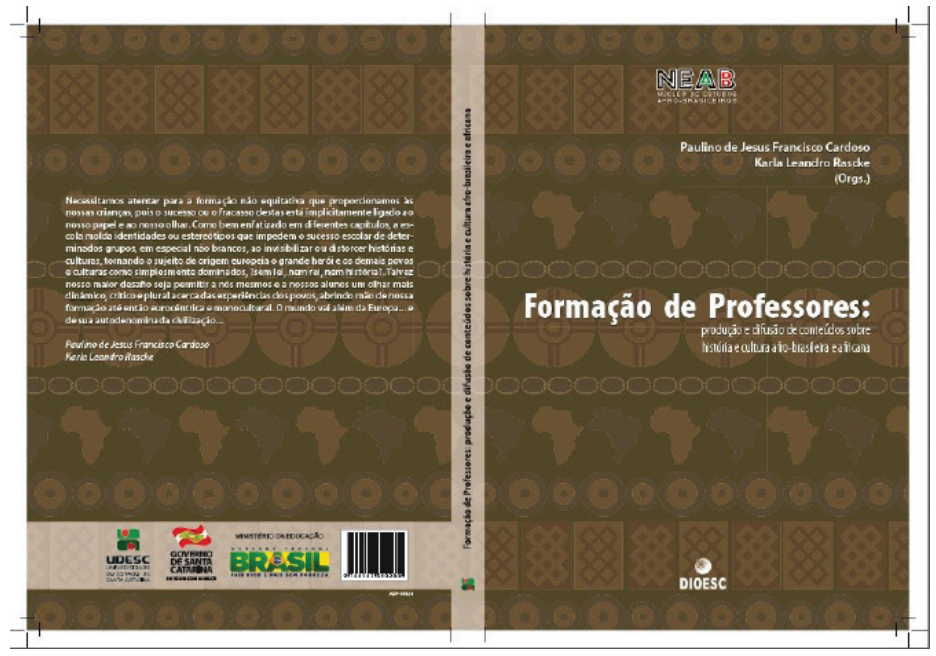

Fonte: Acervo do NEAB-UDESC, 2014. 
Karla Leandro Rascke - Paulino de Jesus Francisco Cardoso - Graziela dos Santos Lima Ana Julia Pacheco

Nosso intuito centrou-se em apresentar textos, imagens e diferentes materiais que representem africanos(as) e afrodescendentes e as suas "realidades desvinculados da escravidão, do sentido exótico, da miséria, das doenças, da fome e dos conflitos é de grande valor elucidativo. (...) transformar o papel comumente delegado à África na trajetória histórica da humanidade" (OLIVA, 2006, p. 198).

\section{Ambiente virtual de aprendizagem (AVA) e encontros presenciais}

Oferecido para professoras e professores da rede básica de ensino do estado de Santa Catarina, tanto pública como privada, a modalidade do curso UNIAFRO IV foi semipresencial: por meio de encontros presenciais (40h) nas cidades de Chapecó, Criciúma, São José, Joinville e Lages e das atividades à distância (140h) através da Plataforma Moodle da UDESC somando uma carga horária total de 180h. Segundo Borges (2005, p. 3), a modalidade de educação semipresencial significa a reelaboração em outros patamares da modalidade de educação presencial, com diferentes atividades, métodos, processos e assim, distintas concepções e paradigmas educacionais.

Figura 3 - Mapa de Santa Catarina (alterado pelos autores, referenciando os polos do curso UNIAFRO IV).

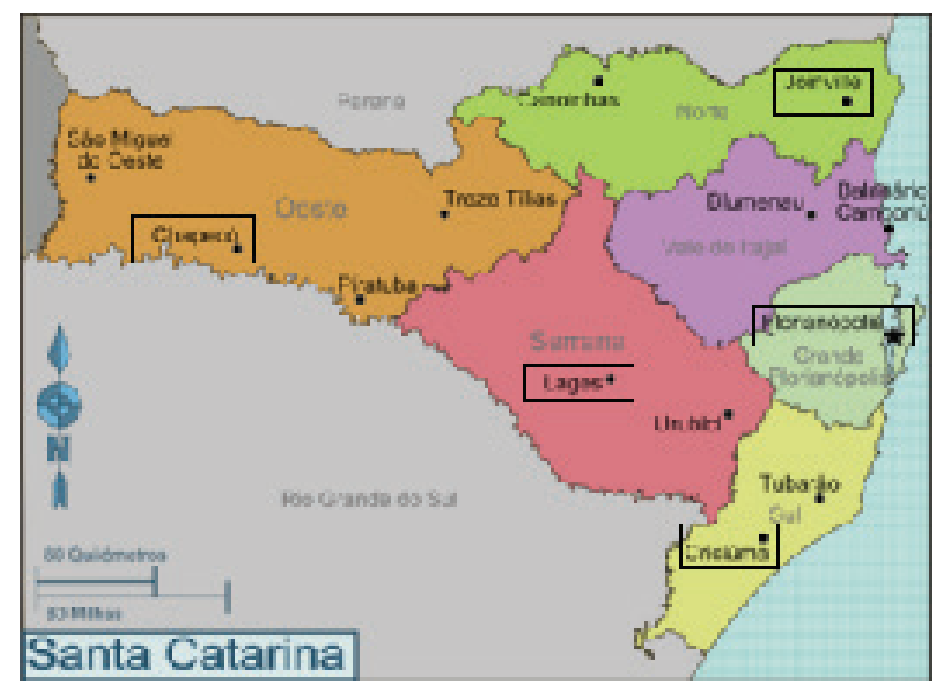

Fonte: <http://wikitravel.org/pt/Santa_Catarina>.

Em seu caráter presencial, o curso foi pensado estrategicamente para atender todo estado, conferindo a cada região de Santa Catarina uma cidade-polo, onde, aglutinando cursistas de municípios próximos, ocorreram os encontros presenciais. Como mostra o mapa, a cidade de Chapecó, atendeu o público oeste; Criciúma, os professores e professoras da região sul; São José ${ }^{10}$ abrigou a região da grande Florianópolis; Joinville atendeu ao norte e também o vale do Itajaí; e Lages, a região serrana catarinense. 
As atividades presenciais foram planejadas em duas partes, ocorrendo aos sábados nas cidades. No período matutino (4h), pensando em atividades mais práticas, os cursistas participaram de oficinas temáticas acerca da história e cultura Africana e Afro-Brasileira e relações étnico-raciais ministradas pelos(as) Oficineiros(as) do cur$\mathrm{so}^{11}$. As oficinas ofertadas durante o curso foram: Máscaras Africanas; Contação de histórias; Religiosidade de matriz Africana; Capoeira; O livro didático, os africanos e os Afrodescendentes; e Arte e Literatura Afro-Brasileira.

Figura 4 - Exposição da oficina $\mathrm{O}$ livro didático, os africanos e os afrodescendentes, realizado no segundo encontro presencial em São José, 05/04/2014.

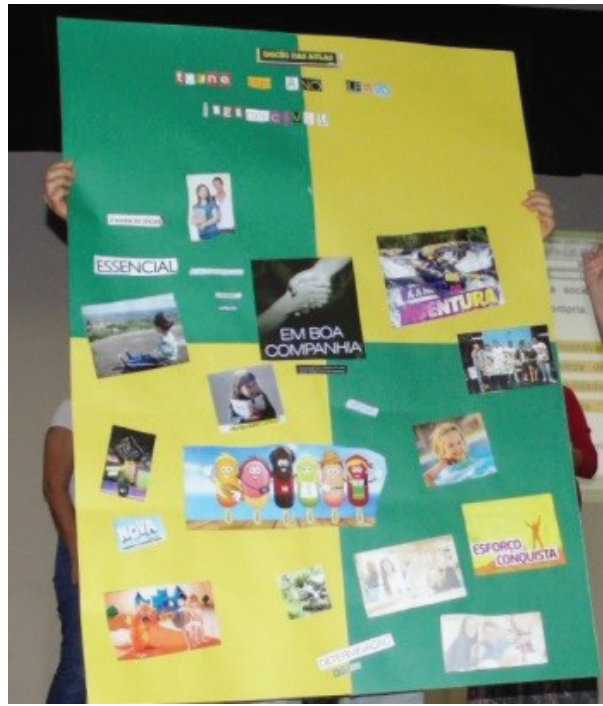

Fonte: Acervo do Núcleo de Estudos Afro-Brasileiros (NEAB/UDESC).

No período vespertino (4h), ocorria a segunda parte do encontro presencial, momento de debates relativos aos conteúdos do módulo do curso trabalhado (cada encontro presencial discutia um Módulo do curso), com a presença de um(a) professor(a) formador(a) mediando as discussões. Os(as) professores(as) formadores(as) eram responsáveis pela introdução dos capítulos do material didático elaborado especialmente para o curso, nos encontros presenciais. Compuseram a equipe de formadores(as) diferentes professores(as) especialistas na temática, sendo que todos(as) os(as) formadores(as) também atuaram na construção dos materiais didáticos do curso, ou seja, na composição dos capítulos em cada um dos módulos e também na organização de materiais complementares disponibilizados na plataforma moodle.

É preciso salientar que em cada encontro presencial, dois/duas professores(as) eram direcionados para cada polo, alternando as cidades a cada novo encontro. Cada professor(a) oficineiro(a) e professor(a) formador(a) eram acompanhados(as) também pela monitora do polo, encarregada de ajudar a organizar o encontro. Nes- 
Karla Leandro Rascke - Paulino de Jesus Francisco Cardoso - Graziela dos Santos Lima Ana Julia Pacheco

te caso, a cada encontro, cada cidade recebia professores(as) diferentes, tanto oficineiros(as), quanto formadores(as), possibilitando o contato com atividades das várias áreas de conhecimento e a troca de experiências com os diferentes professores e professoras cursistas.

Em seu modo à distância, o curso utilizou a Plataforma Moodle (http:// moodle.udesc.br/), ambiente virtual de aprendizagem, empregada pela Universidade do Estado de Santa Catarina (UDESC), cuja contínua parceria desde 2006 entre o NEAB/UDESC e o Centro de Educação a Distância (CEAD) vem proporcionando a realização de cursos de formação continuada promovidos pelo Núcleo.

A EaD tem sido uma possibilidade ampla e de qualidade para a formação continuada de professores/as oferecida pelo NEAB/ UDESC, por atingir um público diverso, de diferentes lugares do Estado de Santa Catarina ou do país, permitindo que a temática das relações raciais seja discutida e reelaborada. (CARDOSO; RIBEIRO; LIMA; RASCKE; PACHECO; JESUS, 2014, p. 11).

Segundo a Comunidade Moodle Brasil (http://www.moodlebrasil.org/), a plataforma é um dos ambientes virtuais mais utilizados mundialmente, devido a sua simplicidade de uso, grande flexibilidade operacional e de configuração. Sobre sua praticidade, o ambiente Moodle reúne recursos que possibilitam o desenvolvimento de atividades de ensino e aprendizagem através da internet, sendo utilizado por educadores(as), permitindo que o(a) professor(a) formador(a) ou o(a) professor(a) tutor(a) também crie e gerencie o ambiente virtual sem necessidade de maiores saberes tecnológicos (SILVA; RIBEIRO; MANDAJI; CONSOLO, s/d, p.4).

Para "abrigar" os(as) professores(as) inscritos(as) no curso "Formação de Professores: produção e difusão de conteúdos sobre história e cultura africana e afro -brasileira" - integrante das ações do Projeto Diversidade Étnica na Educação, financiado pelo Programa UNIAFRO do Governo Federal -, de maneira distribuída, o curso manteve abertas 10 salas virtuais no moodle, com no máximo 60 cursistas cada uma.

Figura 5 - Sala 1 do curso no ambiente virtual de aprendizagem (moodle).

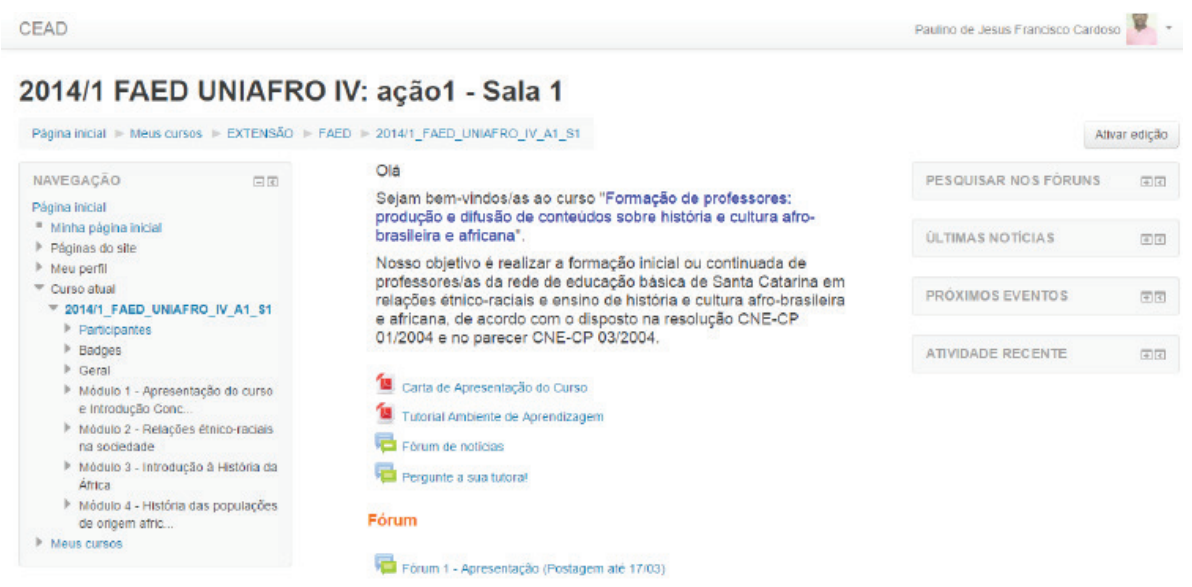

Fonte: <http://www.moodle.udesc.br/>. 
Cada sala possuía um(a) professor(a) tutor(a), com papel fundamental na construção do saber em espaço virtual, atuando enquanto mediador do curso junto ao professor -que realizava o curso na condição de "cursista" -, responsável por articular as discussões teóricas e práticas nos fóruns, esclarecer dúvidas, estimulando a não desistência e, ao mesmo tempo, participando do processo de ensino/ aprendizagem dos cursistas. Cada sala virtual no moodle contava com a supervisão e o acompanhamento diário de um(a) professor(a) tutor(a) atuante na mediação entre conteúdos dos capítulos e materiais de apoio, bem como debatendo nos fóruns realizados semanalmente e, ainda, desenvolvendo diálogos referentes aos encaminhamentos e às questões pontuadas nos encontros presenciais que aconteciam na abertura de cada módulo.

Há várias maneiras de definir o conceito. A tutoria pode ser entendida como uma ação orientadora global, chave para articular a instrução e o educativo. O sistema tutorial compreende, desta forma, um conjunto de ações educativas que contribuem para desenvolver e potencializar as capacidades básicas dos alunos, orientando-os a obterem crescimento intelectual e autonomia, e para ajudá-los a tomar decisões em vista de seus desempenhos e suas circunstâncias de participação como aluno. (SOUZA; SPANHOL; LIMAS; CAS$\mathrm{SO}, 2004, \mathrm{~s} / \mathrm{p})$.

Tradicionalmente, nos cursos de formação a distância ministrados pelo NEAB-UDESC, a participação efetiva do cursista se dá por meio de sua manifestação nos Fóruns e na entrega de uma atividade final. $\mathrm{O}$ fórum é uma ferramenta de interação coletiva assíncrona, que propicia o debate de questões relacionadas aos temas abordados nas disciplinas e a troca de experiências entre professores(as) tutores(as) e professores(as) da educação básica em formação, e também de todos(as) que realizavam o curso entre si (UDESC, p. 6 s/d).

No curso "Formação de Professores" não foi diferente, tendo sido elaborados um total de cinco fóruns, organizados em quatro módulos, que buscavam "amarrar" as discussões estabelecidas a partir do material didático, junto ao material complementar e a mediação do(a) professor(a) tutor(a). É importante ressaltar que, para todos os módulos do curso disponibilizamos, além do material didático próprio, alguns materiais complementares, nesse caso, textos, jogos, vídeos e músicas relacionadas à temática estudada no módulo.

O primeiro fórum, voltado para adaptação do cursista com o ambiente virtual de aprendizagem, propôs a apresentação de cada participante e suas expectativas em relação ao curso. $\mathrm{O}$ segundo fórum abriu o primeiro módulo do curso intitulado "Apresentação do curso e Introdução Conceitual", que abordou a discussão de alguns conceitos imprescindíveis para a introdução aos estudos da temática africana e afro -brasileira, e as propostas das DCN para educação das relações étnico-raciais a partir da trajetória de lutas do Movimento Negro, de intelectuais e militantes antirracistas. O terceiro fórum do curso, encontrado no módulo dois, "Relações étnico-raciais na sociedade", abrigou a temática das relações raciais na escola e a história do Movimento Negro no Brasil na perspectiva da luta pela educação. 
No módulo três, "Introdução a História da África”, o quarto fórum buscou articular a história do continente Africano, perpassando entre a história de seus antigos reinos e sociedades até a descolonização e a África contemporânea. No último fórum, disposto no último módulo do curso, intitulado "História das populações de origem africana no Brasil", discutiu-se brevemente apontamentos sobre a presença africana no Brasil desde o século XVI até os dias atuais, centrando também na história das populações de origem africana em Santa Catarina. Este último fórum também incluiu o estudo das manifestações afro-brasileiras, pensando artes, literatura e religiosidade, bem como também reflexões do tempo presente em torno das demandas por políticas públicas.

Os fóruns tinham data limite para a primeira postagem, e a cada resposta, o(a) professor(a) tutor(a) indicativa sugestões e propunha aprofundamentos/considerações, sendo que o(a) cursista novamente recebia um prazo para dialogar com as questões pontuadas pelo(a) professor(a) tutor(a). Além dos 5 fóruns, o curso também exigiu a elaboração de uma atividade final, pautada na elaboração de um projeto de ensino-aprendizagem, a partir da articulação de algumas das temáticas estudadas durante o curso, formulada a partir do contexto escolar de inserção do(a) cursista. $\mathrm{O}$ objetivo da atividade final propunha contribuir para a implementação dos princípios e fundamentos contidos nas Diretrizes Curriculares Nacionais para a Educação das Relações Étnico-raciais e para o Ensino de História e cultura africana e afro-brasileira.

\section{Dos resultados I: trabalhos finais dos cursistas}

Os trabalhos finais do curso foram pensados a partir do enfoque e do público participante, ou seja, professores e professoras das redes de ensino básico. Neste sentido, como atividade de fechamento, propusemos a organização de um plano de ensino, composto por tema, disciplina(s) envolvida(s), duração da proposta, série/ano, apresentação do projeto ${ }^{12}$, justificativa de realização, objetivos, conteúdos, metodologia, material didático/recursos, avaliação e referências bibliográficas.

Cada plano foi elaborado por um(a) cursista de acordo com sua área de atuação e formação, tendo o acompanhamento do(a) professor(a) tutor(a) de cada sala do moodle. As atividades finais passaram pelo parecer do(a) tutor(a) de cada sala e foram reelaboradas a partir de considerações/sugestões deste(a) corretor(a), no intuito de ampliar discussões, estreitar objetivos, esmiuçar e detalhar a proposta a ser desenvolvida na escola onde o(a) cursista atua.

Os temas enfocados pelos(as) professores(as) cursistas demonstraram múltiplas possibilidades de abordagem, de acordo com as diferentes áreas/disciplinas escolares dos currículos escolares. Assim, percebemos que todas as áreas podem desenvolver ações e apontar possibilidades de implementação da Lei Federal 10.639/03 em suas turmas e escolas, pois há uma multiplicidade de abordagens temáticas, conceituais e analíticas para tal.

Indicando alguns dos temas abordados nestes trabalhos finais, destacaremos alguns de diferentes disciplinas: história e cultura afro-brasileira em espaço de 
Educação de Jovens e Adultos; as lutas de afrodescendentes nos séculos XX e XXI; ritmos, tambores e grilhetas; protagonismo negro através da literatura infantil; danças circulares; África e artes; livros, revistas e histórias têm cor?; projeto melanina; escravidão e resistência negra; conhecendo o corpo humano e os diferentes fenótipos; preconceito e discriminação racial no futebol; literatura africana; afrodescendentes em Santa Catarina, etc. Estes constituem exemplos das temáticas desenvolvidas e envolvem as múltiplas áreas do conhecimento, enfatizando que vários destes projetos propunham ação conjunta entre disciplinas diferentes (atuação multidisciplinar).

Enfocamos no curso, conforme esboçado neste artigo, que a proposta envolve pensar as múltiplas Áfricas e a história afro-brasileira para além da escravidão comumente abordada em livros didáticos e materiais diversos que remetem à presença africana nas Américas. Como bem salienta Anderson Oliva, a história e a historiografia africana merecem atenção particularizada (2006, p. 195), bem como as abordagens e perspectivas sobre a participação de origem africana na história e cultura brasileiras necessitam de enfoques que apontem para suas dinâmicas de organização, formas de sociabilidades e laços de solidariedades, redes de relacionamento e articulação, constituição de movimentos negros e lutas antirracistas, ampliando olhares sobre resistências e memórias cotidianas vivenciadas nestes séculos de Áfricas em terras brasileiras.

\section{Dos resultados II: avaliação geral dos impactos do curso}

Procuramos, a partir da organização da proposta do curso "Formação de Professores: produção e difusão de conteúdos sobre história afro-brasileira e africana", enfatizar a importância da atuação de professores e professoras enquanto multiplicadores(as) dos conhecimentos acerca das Áfricas, da diáspora e das relações raciais no Brasil, potencializando educadores e educadoras e tornarem-se comprometidos(as) com uma visão de mundo que amplie olhares para além da cultura ocidental, europeia, cristã. Cremos na perspectiva de que podemos "vencer determinações de sistema mundo centrado na cosmovisão representativa de uma única raiz étnico-racial" (SILVA, 2007, p. 501).

Atuamos junto ao estado de Santa Catarina, atendendo cidades de cinco regiões que formaram polos de apoio e encontros presenciais. Ao todo, dos 600 professores inscritos iniciantes do curso, apenas 132 professores(as) finalizaram o curso com êxito e receberam certificação de 180 horas de atividades, entre oficinas, formações presenciais e atividades na plataforma moodle. Cada cursista compõe uma possibilidade de multiplicação dos debates em sua escola, cidade e área de atuação, ampliando visões e perspectivas a partir das reflexões do curso e dos materiais utilizados. Um dos critérios para certificação envolveu a participação em todas as atividades da plataforma moodle e participação em 4 dos 5 encontros presenciais, salvo algum motivo maior.

Algumas dificuldades, dada a amplitude de abrangência do estado, foram presentes e devem ser ressaltadas para experiências futuras e possibilidades de atuação. Desenvolver ações simultâneas de formação de 5 polos distintos constituiu um grande desafio, contando com a parceria de diferentes instituições públicas que receberam nossa equipe e os(as) cursistas em seus espaços físicos. Também tivemos que lidar com inúmeras desistências ao longo da trajetória do curso, visto que muitos(as) professo- 
res(as) possuíam carga horária de 40 a 60 horas, inviabilizando, em certos momentos, a organização para os estudos necessários e atividades nos polos.

Essa foi uma das questões mais apontadas pelos(as) professores(as) desistentes, destacando a falta de tempo para a formação continuada, pois lecionando entre 40 e horas por semana, as possibilidades de acompanhamento dos fóruns, leitura dos textos e encontro presencial aos sábados, mesmo que em número reduzido, tornavamse atividades incompatíveis com a excessiva carga de trabalho docente. Infelizmente, em poucas redes de ensino ocorre liberação para formação continuada "desvinculada" da própria oferta da rede.

Entretanto, para além das dificuldades envolvendo o considerável número de desistências ao longo do curso e também a logística para os encontros presenciais, alguns desafios demandam reflexões para novas etapas e experiências neste âmbito, como propostas de cursos mais articulados a excessiva carga horária docente e estratégias de articulação mais afinadas com as redes de ensino e possibilidade de liberação dos(as) professores(as) com destino de alguma carga horária que permita essa imersão.

Alguns resultados foram positivos e permitem vislumbrarmos os avanços na temática e o comprometimento de professores e professoras que, ademais suas múltiplas tarefas cotidianas, propuseram-se aprender e dialogar com novos conhecimentos, perspectivas e abordagens. Assim, a produção do livro didático do curso e sua distribuição aos cursistas constituiu ponto forte no trabalho, bem como os interessantes planos de ensino sistematizados para a atividade final do curso, propostas efetivadas em sala de aula e apresentadas no encontro presencial de encerramento do curso.

Importa destacar ainda, o potencial amplo das diferentes áreas do conhecimento que participaram do curso, com profissionais de letras, pedagogia/educação, história, geografia, biologia, ensino religioso, literatura, inglês, matemática, educação física, sociologia, artes, português e psicologia. Além disso, oportunamente, cabe ressaltar como ponto positivo a boa articulação entre os debates e as formações dos encontros presenciais com as discussões e atividades propostas na plataforma moodle, envolvendo professores(as), professores(as) tutores(as) e formadores(as).

Empenhamo-nos em promover a formação de cidadãos e cidadãs conscientes de suas ações e responsabilidades quanto à construção de uma sociedade mais igualitária no exercício de direitos e na criação de oportunidades. Assim, o curso pautou temas e questões de uma agenda política, social e ética preocupada com a transformação social. Compreendemos os limites da formação continuada docente e a experiência desse curso dimensionou desafios em torno da educação das relações étnico-raciais, as demandas das escolas por formação adequada à temática, mas, ao mesmo tempo, as limitações existentes em nosso modelo atual de educação e formação docente continuada.

Acreditamos que, mesmo diante do número menor de professores(as) certificados(as) pelo curso em relação ao potencial inicial que era de 600, aqueles(as) que receberam a certificação no curso, estão aptos a debates e situações oriundas da escola, da sociedade e das disciplinas em que lecionam, dialogando com perspectivas 
em torno das Áfricas, da diáspora e das relações étnico-raciais mais apropriadamente, efetivando uma postura antirracista e preocupada com uma educação integradora, capaz de alcançar anseios e objetivos de cidadãos e cidadãs brasileiros.

\section{Considerações finais}

A realização do curso "Formação de Professores", integrante do projeto Diversidade Étnica na Educação, financiado com recursos do MEC-SECADI por meio do edital UNIAFRO IV, pelo NEAB/UDESC no ano de 2014, permitiu a capacitação de professoras e professores, distribuídos por todo o estado de Santa Catarina, para o ensino de História e Cultura Africana e Afro-Brasileira. Ao mesmo tempo, marca a trajetória dos cursos de formação continuada do Núcleo para a implementação das Leis Federais 10.639/03 e 11.645/08, tendo em vista a abrangência do curso pensado para todo estado e os resultados alcançados juntos aos educadores(as) atendidos(as).

Maria Angélica Zubaran e Petronilha Beatriz Gonçalves e Silva (2012) consideram que a discussão teórico-metodológica em torno da cultura e da história africana e afro-brasileira é um dos vários desafios para a construção de programas e projetos, atividades culturais e políticas para a formação de professores(as), com pedagogias que combatam o racismo e as discriminações na sociedade brasileira.

Nessa perspectiva, os Núcleos de Estudos Afro-Brasileiros (NEABs) das universidades do país têm ampliado suas atividades de pesquisa, ensino e extensão universitária com o propósito de apoiar e garantir a implantação do determinado na Lei. Concordamos, deste modo, que cabe aos NEABs, num diálogo com os movimentos sociais, atuar efetivamente no movimento de discussão e formação em história e cultura afro-brasileira e africana e relações étnico-raciais, com olhar atento às instituições de ensino, mas também objetivando atender demandas da comunidade envolvente (CARDOSO; RIBEIRO; LIMA; RASCKE; PACHECO; JESUS, 2014, p. 12). Atuamos no sentido de possibilitar que nossos(as) docentes, das diferentes redes de ensino, "identifiquem e superem as armadilhas teóricas e os argumentos que lançam sobre a África um olhar pejorativo"(OLIVA, 2006, 212).

\section{Referências}

ABREU, Ticiane Caldas de. África no ensino de História em Santa Catarina: impactos da formação inicial docente e seus efeitos na prática do ensino de África. Trabalho de Conclusão de Curso (Graduação em História) - Universidade do Estado de Santa Catarina (UDESC). Florianópolis, 2017.

BORGES, Martha Kschny. Educação semipresencial: desmistificando a educação a distância. In: Anais do XII Congresso Internacional de Educação a Distância da ABED, 2005. p. 1-12.

COELHO, Wilma Nazaré Baía. SANTANA, Moises; CARDOSO, Paulino de Jesus Francisco. O Enfrentamento do racismo e preconceito no Brasil: A experiência de Neab's. Itajaí: Casa Aberta, 2014.

CARDOSO, Paulino de Jesus Francisco; RIBEIRO, Neli Góes; RASCKE, Karla Leandro; LIMA, Graziela dos Santos; PACHECO, Ana Júlia; JESUS, Maria Gerlane Santos. Formação para a educação das relações étnico-raciais: experiências em cursos de formação continuada NEAB/UDESC. Revista em Extensão (Online), v. 13, p. 9-19, 2014. 
Karla Leandro Rascke - Paulino de Jesus Francisco Cardoso - Graziela dos Santos Lima Ana Julia Pacheco

CARDOSO, Paulino de Jesus Francisco; RASCKE, Karla Leandro (Orgs.). Formação de professores: produção e difusão de conteúdos sobre história e cultura afro-brasileira e africana. $1^{\mathrm{a}}$. ed. Florianópolis: DIOESC, 2014.

CARDOSO et al. Formação continuada em educação das relações étnico-raciais: o(a) professor(a) tutor(a) na construção do conhecimento. Revista Ibero-Americana de Estudos em Educação, n. 11, vol. 3, 2016, p. 1389-1408.

CARDOSO, Paulino de Jesus Francisco. Em busca de um fantasma: as populações de origem africana em Desterro, Florianópolis, de 1860 a 1888. Revista PADÊ: estudos em filosofia, raça, gênero e direitos humanos. v.2, n.1/7, p. 16, UniCEUB, FACJS.

GARCÊS, Franciele. A inserção da temática africana e afro-brasileira no ensino de Biblioteconomia da Universidade do Estado De Santa Catarina. Trabalho de Conclusão de Curso (Graduação em História) - Universidade do Estado de Santa Catarina (UDESC). Florianópolis, 2016.

HECK, Mariana. Identidades e Multiculturalismo: um estudo acerca do Ensino de História das Áfricas nas Universidades Públicas de Santa Catarina (2011-2012). Trabalho de Conclusão de Curso (Graduação em História) - Universidade do Estado de Santa Catarina (UDESC). Florianópolis, 2013.

HERNANDEZ, Leila leite. A África na Sala de Aula. São Paulo: Selo Negro, 2005.

LEITE, Ilka Boaventura. Descendentes de Africanos em Santa Catarina: Invisibilidade Histórica e Segregação. In: LEITE, Ilka Boaventura. Negros no Sul do Brasil: invisibilidade e territorialidade. Florianópolis: Letras Contemporâneas, 1996.

MANARA, Alécia Saldanha; FREITAS, Indianara. O Trabalho Docente do Professor Tutor na Educação à Distância. In: Anais da 3a Jornada Acadêmica Mestrado em Educação-Unisc. Santa Cruz do Sul: Unisc, 2011. v. 1. p. 01-18. Disponível em: < http://www.unisc.br/portal/ upload/com_arquivo/o_trabalho_docente_do_professor_tutor_na_educaacaao_aa_distaancia. pdf $>$. Acesso em: 4 abr. 2015.

MORTARI, Claudia (Org). Introdução dos Estudos Africanos e da Diáspora. Florianópolis: DIOESC, 2015.

OLIVA, Anderson Ribeiro. A história africana nos cursos de formação de professores: panorama, perspectivas e experiências. Estudos Afro-Asiáticos (UCAM), v. 28, p. 187-220, 2006. Disponível em: <http://repositorio.unb.br/bitstream/10482/6224/1/ARTIGO_Hist\%C3\%B3riaAfricanaCursosForma\%C3\%A7\%C3\%A3oProfessores.pdf $>$. Acesso em 23 de março de 2015.

PACHECO, Ana Júlia. História da África no curso de graduação em História de Instituições Comunitárias de Ensino Superior de Santa Catarina: Perspectivas, avanços e desafios. Trabalho de Conclusão de Curso (Graduação em História) - Universidade do Estado de Santa Catarina (UDESC). Florianópolis, 2014.

PACHECO, Ana Júlia; CARVALHO, Carol Lima; ABREU, Ticiane Caldas de; LELIS, Aline. O cenário da História da África no Ensino Superior: Universidade Federal Fronteira Sul (UFFS), Universidade do Estado de Santa Catarina (UDESC) e Universidade do Extremo Sul de Santa Catarina (UNESC). Pontos de Interrogação: Revista de Crítica Cultural, v. 5, p. 177-192, 2015.

SECADI, Secretaria de Educação Continuada, Alfabetização, Diversidade e Inclusão. Plano nacional de Implementação das diretrizes curriculares nacionais para a educação das Relações Étnico-Raciais e para o ensino de História e Cultura Afro-brasileira e Africana. MEC, Brasília, 2009.

SILVA, Petronilha Beatriz Gonçalves e. Aprender, ensinar e relações étnico-raciais no Brasil. Revista Educação. Porto Alegre/RS, n. 3 (63), p. 489-506, set./dez. 2007. Disponível em: $<$ http://revistaseletronicas.pucrs.br/ojs/index.php/faced/article/download/2745/2092>. Acesso em: 23 mar. 2015. 
SILVA, Maria da Graça Moreira da; RIBEIRO, Renata Aquino; MANDAJI, Mônica; CONSOLO, Adriane Treitero. Guia do Ambiente Virtual de Aprendizagem Moodle - parte 1. s/s. Disponível em: <http://etechoracio.com.br/moodle/file.php/1/guia_moodle_1.pdf $>$. Acesso em: 4 abr. 2015.

SILVA, Mariah Amanda da. Diversidade, Racismo e Multiculturalismo na educação: um estudo da Lei Federal 10.639/03 dos cursos de geografia da UDESC. Trabalho de Conclusão de Curso (Graduação em História) - Universidade do Estado de Santa Catarina (UDESC). Florianópolis, 2016.

SOUZA, Carlos Alberto de; SPANHOL, Fernando José; LIMAS, Jeane Cristina de Oliveira; CASSOL, Marlei Pereira. Tutoria na Educação a Distância. In: $\mathbf{1 1}^{\circ}$ Congresso Internacional de Educação a Distância, 2004, Salvador - BA. Tutoria na Educação a Distância, 2004. Disponível em: <http://www.abed.org.br/congresso2004/por/htm/088-TC-C2.htm>. Acesso em: 5 abr. 2015.

UDESC, Universidade do Estado de Santa Catarina. Tutorial do ambiente de aprendizagem das disciplinas do curso de pedagogia a distância oferecidas pela tutoria virtual. S/d. Disponível em: <http://www.moodle.udesc.br/pluginfile.php/129211/mod_resource/content/1/ Tutorial\%20Ambiente\%20de\%20Aprendizagem.pdf>. Acesso em: 4 abr. 2015.

ZUBARAN, Maria Angélica; SILVA, Petronilha Beatriz Gonçalves. Interlocuções sobre Estudos Afro-Brasileiros: Pertencimento Étnico-racial, memórias negras e patrimônio cultural afro-brasileiro. Currículo sem Fronteiras, v. 12, n. 1, p. 130-140, Jan/Abr 2012. Disponível em: $<$ http://www.curriculosemfronteiras.org/vol12iss1articles/zubaran-silva.pdf $>$. Acesso em: 5 abr. 2015.

\section{Notas}

${ }^{1}$ A Lei Federal n. 10.639/03 sancionada pelo presidente Luiz Inácio Lula da Silva instituiu a obrigatoriedade do ensino de história e cultura afro-brasileira e africana nas redes oficiais de ensino. Esta lei sofreu alterações em 2008, na forma da Lei Federal n. 11.645, com a inclusão de história e cultura indígena.

${ }^{2}$ Programa do Governo Federal criado em 2004, intitulado Programa de Ações Afirmativas para a População Negra nas Instituições Federais e Estaduais de Educação Superior (Uniafro), vinculado à Secretaria de Educação Continuada, Alfabetização, Diversidade e Inclusão.

${ }^{3}$ A respeito das dificuldades de implementação da Lei Federal 10.639/03 nos cursos de Ensino Superior, em especial, ante preocupações com as licenciaturas e a formação docente, consultar as seguintes bibliografias: PACHECO, Ana Júlia. História da África no curso de graduação em história de instituições comunitárias de ensino superior de Santa Catarina: perspectivas, avanços e desafios. Trabalho de Conclusão de Curso (Graduação em História) - Universidade do Estado de Santa Catarina (UDESC). Florianópolis, 2014; ABREU, Ticiane Caldas de. África no ensino de História em Santa Catarina: impactos da formação inicial docente e seus efeitos na prática do ensino de África. Trabalho de Conclusão de Curso (Graduação em História) - Universidade do Estado de Santa Catarina (UDESC). Florianópolis, 2017; GARCÊS, Franciele. A inserção da temática africana e afro-brasileira no ensino de Biblioteconomia da Universidade do Estado De Santa Catarina. Trabalho de Conclusão de Curso (Graduação em História) - Universidade do Estado de Santa Catarina (UDESC). Florianópolis, 2016; PACHECO, Ana Júlia; CARVALHO, Carol Lima; ABREU, Ticiane Caldas de; LELIS, Aline. O cenário da História da África no Ensino Superior: Universidade Federal Fronteira Sul (UFFS), Universidade do Estado de Santa Catarina (UDESC) e Universidade do Extremo Sul de Santa Catarina (UNESC). Pontos de Interrogação: Revista de Crítica Cultural, v. 5, p 177-192, 2015; SILVA, Mariah Amanda da. Diversidade, Racismo e Multiculturalismo na educação: um estudo da Lei Federal 10.639/03 dos cursos de geografia da UDESC. Trabalho de Conclusão de Curso (Graduação em História) - Universidade do Estado de Santa Catarina (UDESC). Florianópolis, 2016. 
4 "Dentre os inúmeros ambientes virtuais de aprendizagem (AVA), para este trabalho desenvolvido pelo NEAB-UDESC na formação continuada de professores (as), utilizamos a Plataforma Moodle (Modular Object-Oriented Dynamic Learning Environment), que permite a gestão de cursos a distância, por meio de um software livre desenhado para auxiliar educadores (as) a criar cursos on-line com ferramentas e layouts personalizados às demandas e interesses de cada instituição, centro de ensino ou curso." Consultar: CARDOSO, Paulino de Jesus Francisco et al. Formação continuada em educação das relações étnico-raciais: o(a) professor(a) tutor(a) na construção do conhecimento. Revista Ibero-Americana de Estudos em Educação, n. 11, vol. 3, 2016, p. 1389-1408.

${ }^{5}$ Cada módulo possuía subdivisões em capítulos.

${ }^{6}$ A equipe de professores(as) formadores(as) contratada pelo NEAB-UDESC, por meio do projeto de formação de professores(as) contemplado por edital do MEC-SECADI, era composta por membros vinculados(as) ao Núcleo, seja em ações de pesquisa, ensino ou extensão. Cada contratado(a) recebeu pela função desempenhada no curso, seja professor(a) formador(a), professor(a) conteudista, professor(a) tutor(a), supervisão pedagógica e coordenação de projetos, além de bolsistas de graduação vinculados(as) à própria UDESC. A nomenclatura das funções exercidas pelos integrantes da equipe manteve-se semelhantes às terminologias utilizadas pelo sistema Universidade Aberta do Brasil (UAB) em alguns casos, embora a atribuição de atividades e o papel de cada profissional tenha sido explicitada quando da contratação de cada um(a), não seguindo os modelos e os padrões vigentes no sistema UAB, informando ainda que o curso não contou com bolsas deste sistema, sendo totalmente financiado pelo edital UNIAFRO IV, com contrapartida da Universidade do Estado de Santa Catarina. A UAB possui um sistema, gerenciamento e organização, mas nos cursos que ofertamos, dadas as particularidades, os cuidados com a temática, as abordagens, a estrutura e o financiamento recebido, seguimos metodologia e estratégias próprias.

${ }^{7}$ A historiografia catarinense, bem como os meios de comunicação em massa construíram uma imagem de Santa Catarina como estado branco europeu, em virtude da grande imigração europeia recebida em fins do século XIX e início do século XX. Essa construção contribuiu para a invisibilização de outros inúmeros povos e grupos culturais componentes desse estado. A respeito dessa invisibilidade, por exemplo, em relação às populações de origem africana em Santa Catarina e a super-representação de imigrantes europeus no imaginário local e nacional, consultar as seguintes bibliografias: LEITE, Ilka Boaventura. Descendentes de Africanos em Santa Catarina: Invisibilidade Histórica e Segregação. In: LEITE, Ilka Boaventura. Negros no Sul do Brasil: invisibilidade e territorialidade. Florianópolis: Letras Contemporâneas, 1996; CARDOSO, Paulino de Jesus Francisco. Em busca de um fantasma: as populações de origem africana em Desterro, Florianópolis, de 1860 a 1888. Revista PADÊ: estudos em filosofia, raça, gênero e direitos humanos. v.2, n.1/7, p. 16, UniCEUB, FACJS.

${ }^{8} \mathrm{O}$ curso contou com 14 capítulos sobre educação das relações étnico-raciais, história das Áfricas e da diáspora, sendo organizados em módulos, conforme distribuição mencionada.

${ }^{9}$ Elaboraram os materiais didáticos do curso os seguintes(as) professores(as): Prof. Dr. Paulino de Jesus Francisco Cardoso, Prof. Dr. Amailton Magno Azevedo, Profa. Ma. Tamelusa Ceccato Amaral, Profa. Dra. Claudia Mortari, Prof. Me. Fábio Amorim Vieira, Profa. Ma. Maristela dos Santos Simão, Profa. Ma. Karla Leandro Rascke, Prof. Me. Angelo Renato Biléssimo e Profa. Me. Jeruse Maria Romão.

${ }^{10}$ Os dois primeiros encontros presenciais na região da Grande Florianópolis aconteceram em São José, devido a parceria realizada entre o NEAB-UDESC e a Secretaria de Educação Municipal de São José, município vizinho a Florianópolis. Os demais encontros aconteceram na capital, na própria UDESC. 
11 "Outro fator importante no desenvolvimento dos cursos de formação foi contar com a presença de militantes históricos(as) da luta antirracista do estado de Santa Catarina e do Brasil que acompanharam, desenvolveram e agora implementam a Lei Federal 10.639/03, como o professor Paulino de Jesus Francisco Cardoso, coordenador do projeto e conteudista na elaboração do material didático do curso, a professora Jeruse Maria Romão, formadora, oficineira e conteudista, o professor Walmir Brito, educador, conhecido como mestre Jimmy Wall na capoeira, e a professora Estela Cardoso, tutora e oficineira. Toda a equipe de profissionais e cursistas compartilharam experiências e aprendizados com estes (as) militantes, intelectuais e educadores(as). Vidas em que a esperança de um Brasil com equidade racial e social se fazem possíveis, pois conhecer suas histórias nos inspira, apontando que suas vidas, não raras vezes, se mesclam na participação e construção de um Brasil plural e não racialista”. Consultar: CARDOSO et al., 2016, p. 1394. Também compuseram a equipe de oficineiros(as) as professoras Ma. Maristela dos Santos Simão, Me. Cristiane Mare da Silva e Ma. Patrícia Maria Alves e o professor Me. Angelo Renato Biléssimo.

${ }^{12} \mathrm{O}$ plano de ensino proposto por cada um(a) dos(as) professores(as) participantes da formação deveria ser realizado na forma de um projeto na unidade de educação onde atuava. Assim, de acordo com cada área de formação - História, Geografia, Português, Biologia, Educação Física, etc. -, a intenção era que cada professor(a) pudesse desenvolver em sua área atividades, abordagens e discussões em torno da temática das Áfricas, diáspora e educação das relações étnico-raciais, procurando inserir tais perspectivas em suas aulas, ao longo do ano. O período de cada atuação proposta variou no grupo, sendo desde ações mais pontuais, envolvendo poucas aulas, até ações que demandavam reflexões ao longo do ano letivo inteiro. Estas propostas e os resultados alcançados por cada professor(a) foi apresentado no último encontro presencial do curso, momento de socialização e encerramento dos estudos.

* Docente na Faculdade de História da UNIFESSPA e doutora em História Social pela Pontifícia Universidade Católica de São Paulo, São Paulo, Brasil.

** Professor doutor da Universidade do Estado de Santa Catarina, Florianópolis, Santa Catarina, Brasil.

**** Mestra em Gestão da Informação pela Universidade do Estado de Santa Catarina, Florianópolis, Santa Catarina, Brasil.

***** Mestra em História pela Universidade Federal do Rio Grande do Sul, Porto Alegre, Rio Grande do Sul, Brasil.

\section{Correspondência}

Ana Júlia Pacheco - Universidade do Estado de Santa Catarina. Núcleo de Estudos Afro-Brasileiros da Universidade do Estado de Santa Catarina. Avenida Madre Benvenuta, 2007. Itacorubi. CEP: 88035-001. Florianopolis, Santa Catarina, Brasil.

E-mail:karlaleandro@gmail.com - paulino.cardoso@gmail.com - graziela.dsl@gmail.com - anajulia.hp@ gmail.com

Recebido em 30 de novembro de 2016

Aprovado em 19 de dezembro de 2017 
